\title{
Educación Ambiental e Educación para a Cidadanía Global: encontro de movementos educativos?
}

\section{Environmental Education and Education for Global Citizenship: encounter of educational movements?}

\author{
Araceli Serantes-Pazos \\ Universidade da Coruña
}

\begin{abstract}
Resumen
A Educación Ambiental (EA) é un movemento educativo que xurde nos anos 60, como resposta ás evidencias de deterioro ambiental e da man de científicas/os, naturalistas e dos incipientes grupos ecoloxistas; pola súa banda, a Educación para o Desenvolvemento (EpD), que xurde tras a II Guerra Mundial, é a resposta educativa solidaria fronte ao somentemento como forma de relación entre os pobos (fundamentalmente do Norte sobre o Sul), e faino da man de grupos pacifistas, relixiosos ou partidos políticos. Ambos os dous configúranse como movementos educativos internacionais, apoiados por Organismos internacionais, Gobernos nacionais e Grupos locais; nos dous casos hai unha evolución desde o seu posicionamento inicial, dando lugar a 4 etapas no primeiro caso e a 5 xeracións no segundo (a última xeración coñecida como "da Cidadanía Global"). Aínda que tiveron comenzos, obxectivos e actores dispares, estos movementos están nun punto de encontro cos Obxectivos do Desenvolvemento Sostible. A continuación, mostramos as sinerxias e singularidades destes movementos no contexto global, como espazos de transformación e innovación educativa. O contexto da análise traspasa o espazo educativo institucionalizado, no que fixeron especial fincapé nos inicios á hora da intervención directa.

Palabras clave: Educación Ambiental, Educación para o Desenvolvemento, Educación para a Cidadanía Global, Obxectivos do Desenvolvemento Sostible.
\end{abstract}

\begin{abstract}
Environmental Education (EE) is an educational movement that emerged in the $60 \mathrm{~s}$, as a response to the evidence of environmental deterioration, promoted by scientists, naturalists and incipient ecological groups; on the other hand, Education for Development (EfD), which emerged after World War II, is the solidarity educational answer front to the submission as a form of relationship between country (mainly from the North on the South), and it is promoted by pacifist groups, religious or political parties. The two are configured as international educational movements, backed by International Organizations, National Governments, and Local Groups; In both cases there is an evolution from its initial positioning, giving rise to 4 stages in the first case and to 5 generations in the second (the last generation known as "of the Global Citizenship"). Although they had different
\end{abstract}

beginnings, objectives and actors, these movements are in a meeting point with the Sustainable Development Goals. Next, we show the synergies and singularities of these movements in the global context, as spaces for transformation and educational innovation. The context of the analysis goes beyond the institutionalized educational space, which made special emphasis on the beginnings of direct intervention.

Keywords: Environmental Education, Education for Development

\section{Introdución}

A Educación Ambiental (EA) é o ámbito profesional no que levo traballando dende hai 30 anos e, nestes 20 últimos, tamén dende o ámbito académico: é meu espazo de confort. O ámbito da Educación para o Desenvolvemento $(\mathrm{EpD})$ retomeino hai 5 anos, por mor da alianza que establecimos un grupo de profesoras da Universidade da Coruña (UDC) coa ONGD Solidariedade Internacional de Galicia (SI-G). Aínda que tamén tiña experiencia profesional no ámbito da Cooperación para o Desenvolvemento, será no ano 2013 -no que presentamos un proxecto de investigación á Xunta de Galicia para coñecer o impacto educativo que estaban a ter as accións levadas adiante por SI-G nos centros escolares galegos- no que profundizo na filosofía, contidos e metodoloxía da EpD desde un punto de vista empírico e científico ao tempo. Xa levamos 4 anos de andaina conxunta, con 4 proxectos de investigación rematados e un novo recén aprobado, en xullo deste ano. Como froito desta traxectoria, comezamos a traballar desde a perspectiva da Educación para a Cidadanía Global (ECG) ou Educación Global, ámbito no que se encontran, se funden e se confunden a EA e a Epd, ou eso creo.

Este artigo é necesario entendelo como unha reflexión intuitiva -ainda que argumentada- e propositiva, mais que unha fundamentación teórica, que gostaría que así fose nunha futura aportación, e como resultado desta traxectoria. 


\section{A Educación para o Desenvolvemento: concepto e traxectoria}

A EpD é un movemento educativo e social que xurde fronte a devastación da II Guerra Mundial. De carácter profundamente pacifista e solidario, a EpD persegue a solución dos conflitos internacionais a través da cooperación; desde o punto de vista filosófico acepta como documento de referencia a Carta dos Dereitos Humanos, aprobada por Nacións Unidas -Organización Gubernamental creada en xuño de 1945, tamén ao remate da II Guerra Mundial, para manter a paz e a seguridade entre as nacións-. Os seus inicios van estar marcados por 3 feitos chave: o nacemento dos Programas de Cooperación Internacional no seo de Nacións Unidas, o xurdimento de dos 2 bloques antagónicos en Europa e a consecuente Guerra Fría e, por último, os procesos de descolonización xurdidos nesta altura nalgúns países de África e Asia .

Estamos a falar "dun proceso educativo constante que favorece a comprensión das relacións económicas, políticas, sociais e culturais entre o Norte e o Sur, promove valores a actitudes relacionadas coa solidariedade e a xustiza social e busca vías de acción para lograr o desenvolvemento humano e sostible" (Manuela Mesa, 2004).

A EpD é un concepto dinámico en constante revisión, que ten experimentado mudanzas na súa focase; no contexto español, representáse esta traxectoria a través de 5 xeracións (Figura 1):

1. De carácter asistencial, aborda problemas de carencia material, de fame e situaciónns catastróficas, a través de campañas de sensibilización para a recollida de fondos económicos. Ten unha forte pegada caritativa fronte a mirada de xustiza social.

2. De carácter desenvolvista, promove programas para atallar os problemas que impiden o desenvolvemento do Sul, desde os obxectivos e mirada do Norte, que impón o seu modelo de desenvolvemento, coa súa cosmovisión e valores. Baséase na formación e doación teconóloxica para un rápido crecemento.

3. Con posturás críticas e solidarias, consciente das repercusións das estruturas coloniales e da división de forzas centro/periferia, vai traballar co Sul desde o Sul de cara a unha nova orde económica, co protagonismo da cidadanía, en base a valores de xustiza e solidariedade. Parte da propia realidade, da concienciación crítica e da toma de decisións consensuadas.

4. Baseada no desenvolvemento humano e sostible, é a máis achegada aos OBxectivos para o Desenvolvemento Sostible ((NNUU, 2015). Nesta xeración inlúe a dimensión ambiental e de xénro, así como unha dimensión política de inclusión e empoderamento dos pobres. Aúna o respecto á diversidade co respecto ao medio ambiente.

5. Para A Educación Global, enfronta os retos comúns da cidadanía desde o autogoberno. Quizás sexa a xeráción máis revolucionaria, ou al menos a menos institucional. Xa que esixe a reforma das instituciónns, das relacións comercias e dos mercados para promover o "bo goberno". A estratexia é o traballo en rede.

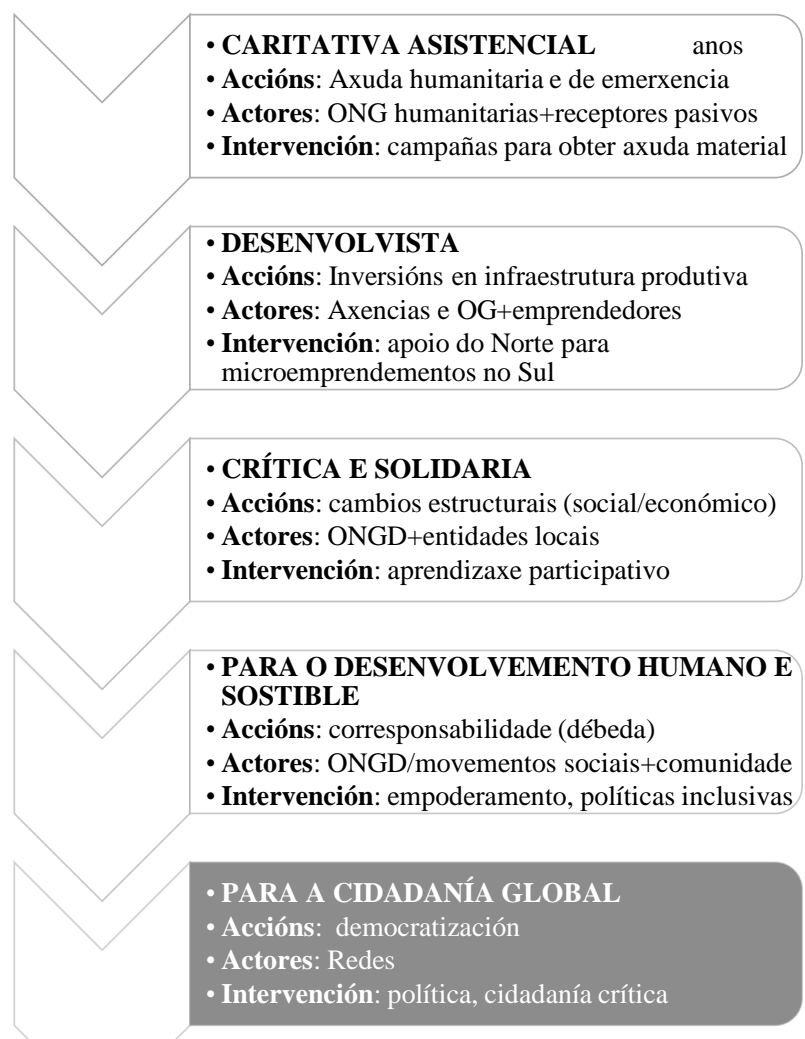

Figura 1. Modelo de 5 xeracións da EpD (Fonte: Manuela Mesa, 2004; Konsue Salinas, 2014. Elaboración propia).

\section{A Educación Ambiental: concepto e traxectoria}

Pola súa banda, son moitas as persoas que sinalan o seu nacemento coa edición a inicios dos anos 60 do libro Silent Spring, de Rachel Carson (1964), onde a científica denuncia os efectos do DDT sobre os ecosistemas e a vida silvestre. $\mathrm{O}$ movemento conservacionista e o incipiente movemento ecoloxista atoparán os argumentos da ciencia nas súas denuncias.

A EA é unha estratexia de acción educativa para promover cambios socioambientais a través do compromiso e a participación da cidadanía. O punto de partida é o recoñecemento da orixe social dos problemas ambientais. No Congreso Internacional sobre Medio Ambiente de Moscú definiríase como "un proceso permanente no que os individuos e as comunidades adquiren conciencia do seu medio e aprenden os coñecementos, os valores, as destrezas, a experiencia e tamén a determinación que lles capacite para actuar, individual e colectivamente na resolución dos problemas ambientais presentes e futuros" (UNESCO-PNUMA, 1987).

O mesmo que no caso da EpD, a EA comparte o mesmo dinamismo e foi evoluindo no tempo, tanto na súa filofofía, como nos obxectivos e modelos de acción (Figura 2): 
1. Inicialmente, a EA estivo moi vinculada ao movemento naturalista ao coñecemento do medio natural e á conservación da natureza; pensaban que con coñecer e transmitir contidos era suficiente. Parte dunha visión conductista e instrumental do medio, que é o obxecto (de estudo e conservación): educar sobre o medio.

2. A etapa predominante está máis vinculada ao sistema educativo. A natureza percívese como un recurso didáctico e confían na capacitación e na sensibilización para mudar as conductas. As propostas baséanse na investigación e descubrimento: educar en o medio.

3. A etapa institucional baséase nas propostas da Educación para o Desenvolvemento que o PNUMA promove a partir de Río '92. O público albo serán os profesionais, pasando os escolares a un segundo plano. Buscan a concienciación para mitigar os problemas ambientais. A relación medio/persoas sigue a ser antropocéntrica e o modelo de aprendizaxe é de carácter significativo e adaptativo: educar para o medio.

4. No último decenio, xurde unha corrente emerxente baseada na participación e nunha visión máis crítica, con propostas de incidencia local desde unha perspectiva global, a través da participación en redes. Parte dun posicionamento biocéntroco e seu modelo educativo é de carácter constructivista e cooperativo de acción directa: educar con o medio.

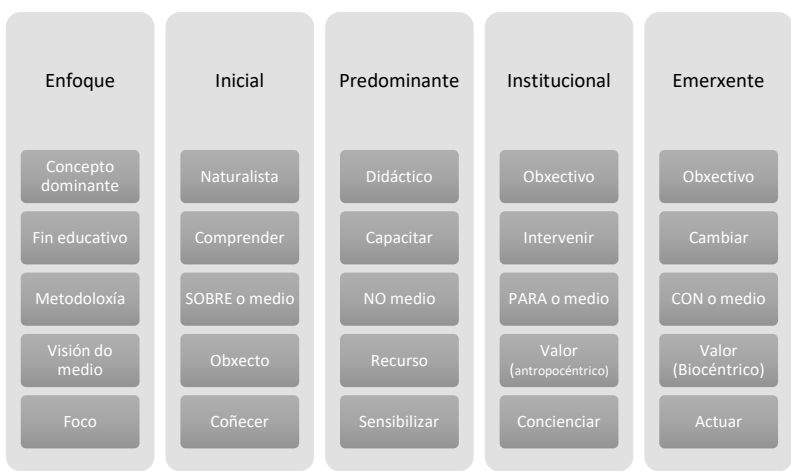

Figura 2. Evolución do conpcepto de Educación Ambiental (A. Serantes, 2010).

A Educación para o Desenvolvemento e a Educación Ambiental: converxencias e diverxencias

Entre as converxencias sinalamos:

$\sqrt{ }$ O punto de partida son os conflictos sociais que van ser abordados dende a perspectiva da intervención educativa e de acción colectiva.

$\sqrt{ }$ En ambos os dous casos, trátase de procesos nos que coexisten e están vixentes as antigas e as actuais perspectivas (etapas ou xeracións, segundo os casos).

$\sqrt{ }$ Son movementos educativos de carácter reactivo ante os conflictos: o primeiro xurde como resposta ás consecuencias da devastación socioeconómica que supuso a II Guerra Mundial e ao colonialismo; a segunda aos efectos da degradación e a contaminación ambiental, en concreto ás acaídas polo uso de pesticidas.

$\sqrt{ }$ Na súa orixe, seu ámbito de acción redúcese ao sistema educativo formal, e persigue ser incluído no curriculum escolar. Na actualidade persiguen a incidencia política directa a través da participación e compromiso das comunidades.

$\sqrt{ }$ Coinciden na necesaria alianza entre o sector privado, a sociedade civil e o sector público para liderar un proceso de desenvolvemento sostible.

$\sqrt{ }$ A súa evolución é similar en canto a que xurden desde os chamados novos movementos sociais (desde os movementos pacifistas e ecoloxistas), para sufrir un proceso de institucialización, no que as Organizacións Gubernamentais e os Gobernos marcaron as liñas de acción, fagocitandoos; na actualidade, en ambos casos aparecen novos actores desde a contracultura.

$\sqrt{ }$ Os Obxectivos para o Desenvolvemento Sostible son un referente que pode facilitar sinerxias, aínda que existen reticencias á hora de asumilos como propios.

$\sqrt{ }$ Finalmente, sinalar que ambas buscan mudar o modelo de desenvolvemento neoliberal.

Entre as diferencias sinalamos:

$\sqrt{ }$ Aínda que as dúas abordan problemas reais, o contexto principal da EpD son os países en desenvolvemento e o da EA é o espazo local, ainda que desde unha perspectiva global, o que se ven denominando como perspectiva glocal.

$\sqrt{ }$ O escenario chave da EpD son os países chamados do Sul ou paises en desenvolvemento, e o da EA é o Planeta como unidade ecosistémica. En ambos os dous casos, as propostas parten das relacións de interdependencia e ecodependencia.

$\sqrt{ }$ Tamén podemos dicir que os promotores destas correntes educativas son bastante similares, aínda que non de todo coincidentes. No caso da EpD estará promovida polas ONG para o desenvolvemento (ONGD), grupos políticos/ sindicais e grupos confesionais (no noso contexto católicos); no caso da EA os promotores serán Movementos de Renovación Pedagóxica MRP (asociación de mestras e mestres comprometidos co cambio educativo), ONG naturalistas/ ecoloxistas e apartir da década dos 80 tamén as institucións públicas.

\section{A Educación para a Cidadanía Global como proposta de acción conxunta}

O concepto de cidadanía relacíónase con outros, como dereitos e deberes, ben no ámbito dun Estado ou ben no ámbito global. Seu referente de mínimos -case cun consenso total- son os Dereitos Humáns e, máis recentemente, os Obxectivos de Desenvolvemento Sostible (NN.UU., 2015) Para Carmen Miguel Juan “o dereito ao desenvolvemento é un dereito que integra o conxunto de todos os dereitos humáns" (2017:17). Cando se fala de Cidadanía Global faise referencia aos dereitos inherentes a todas as persoas, mais tamén a súas identidades, súa cultura, súas cosmovisións, seus 
modelos de relación co Planeta... os primeiros son iguais para toda a humanidade e os segundos son diferenciados.

Vivimos nun mundo diverso, mais interrelacionado e interdependente; os procesos de globalización teñen posibilitado o acceso á información e a modelar unha cidadanía aparentemente máis igual, con soños similares, con modelos de vida baseados en patróns de producción/consumo bastante similares. Unha cidadanía tan diferente en canto a identidade cultural, de xénero, de relixiosa etc. comparte un único territorio, un mesmo espacio: o Planeta Terra, o que en palabras de Martha Nussbaum (1999:20) convírteos en "cidadáns do mundo". Para Vandana Shiva (1998) trátase do espazo político no que non hai dominación e se respectan as diferencias e os intereses lexítimos de cada pobo.

A maior parte dos problemas aos que se enfrenta a comunidade internacional requiren da cooperación dos Estados: enfrontarnos a crise global require dunha cidadanía capaz de implicarse e participar en iniciativas xeneradoras de cambios. A Educación para a Cidadanía Global está orientada á acción transformadora.

"A educación global é unha educación holística que abre os ollos e as mestes da xente ás realidades do mundo, e os sensibiliza para construir un mundo de maior xustiza, equidade e respecto aos dereitos humáns para todos" (Declaración de Educación Global de Maastricht, 2002)

A EpD e a EA atopan un lugar de encontro na Educación Global ao tratarse de procesos educativos que buscan empoderar as persoas a partir do coñecemento da súa realidade, dos factores externos que a determinan e da creación de respostas ao marxen dos sistemas de dominación dos modelos neoliberais.

Si tivéramos que poñer unha data na que se evidencias as sinerxias, quizás poidera ser a Cimeira da Terra en Río de Janeiro (1992). No capítulo 36 da Axenda 21, fai alusión a este encontro de obxectivos: "A educación é fundamental para promover un desenvolvemento sustentable e mellorar a capacidade das persoas para interactuar co seu medio ambiente e os temas vinculados co desenvolvemento" (MMA, 1998:251).

\section{Alguns retos para ir da mán dada}

É imprescindible incluir o enfoque de xénero á hora de planificar acciósn educativas, desde unha perspectiva feminista. Aínda que desde o ámbito da EA existen exemplos de "ecofeminismo" e desde a EpD se debe traballar desde unha perspectiva de xénero, na actualidade segue a ser máis un reto que unha realidade. A proposta de Cidadanía Global recoñece que os sistemas políticos e económicos, de corte patriarcal, están a provocar desigualdade e discriminación, fundamentalmente sobre as mulleres.

A proposta de empoderamento das mulleres fundaméntase en tres formas de poder interrelacionadas (Rodríguez Manzano, 2017:64-65): o "poder para” crear novas posibilidades e accións, o "poder con" a comunidade e grupos de persoas para traballar conxuntamente e o "poder dentro" no que cada muller recoñece a súa potencialidade e sexa capaz de aceptarse, para recoñecer as diferencias que lle permitirá traballar nun plano de igualdade. O punto de partida é a análise da realidade con enfoque de xénero, no que se identifican os principais ámbitos de discriminación, os obstáculos para participar, os programas ou iniciativas de empoderamento existentes e as aspiracións individuais das mulleres (March, Smyth e Mukopadadhyay, 1999).

Outro reto é conseguir análises e miradas máis interculturais e, unha vez máis, este reto sexa máis evidente no ámbito da EA.

Tamén é necesario implicar a poboación en propostas de acción política, así como implicar aos decisores.

Por último, o Cambio Climático debe ser o núcleo central das súas axendas de acción.

\section{Referencias}

Andreotti, V. (2014). Educação para a Cidadania Global - Soft versus Critical. Sinergias-diálogos educativos para a transformação social, $\mathrm{n}^{\circ} 1 \mathrm{pp}$. 57-66.

Carson, rachel (1965). La primavera silenciosa. Barcelona: Luis de Caralt.

March, C., I. Smyth y M. Mukhopadhyay (1999), A Guide to Gender-Analysis Frameworks. Oxford: OXFAM.

MMA (1998). Río 92. Programa 21. Acuerdos. Madrid: Ministerio de Medio Ambiente.

Miguel Juan, C. (2017). Derechos Humanos generales y específicos de las mujeres. En M. Carballo de la Riva (coord.), Género y desarrollo: cuestiones clave desde una perspectiva feminista (pp. 17-47). Madrid: La catarata.

Naussbam, Martha (1999). Los límites del patriotismo: identidad, pertenencia y "ciudadanía mundial". Barcelona: Paidós Ibérica

NN.UU. (2015). Proyecto de documento final de la cumbre de las Naciones Unidas para la aprobación de la agenda para el desarrollo después de 2015. www.un.org/es/comun/docs/?symbol=A/69/L.85

Rodríguez Manzano, I. (2017). De las mujeres al género en el desarrollo: mucho más que un cambio terminológico. En M. Carballo de la Riva (coord.), Género y desarrollo (pp. 49-74). Madrid: La catarata.

Salinas Ramos, K. (2014). Acercando la Educación para el Desarrollo a la escuela. Una mirada internacional, una mirada local. Pamplona: Castuera.

Serantes, A. (2010). Cuatro décadas en la educación ambiental. Janus 2010. Anuario de relações exteriores, $\mathrm{n}^{\circ} 13$, pp. 98-99.

Shiva, V. (1998). La praxis del ecofeminismo: biotecnología, consumo y reproducción. Barcelona: Icaria.

UNESCO-PNUMA (1987) Congreso Internacional de Educación y Formación sobre Medio Ambiente. http://unesdoc.unesco.org/images/0007/000750/07507 2sb.pdf 